\title{
The effect of water uptake on the behaviour of hydrophilic cements in confined environments
}

\author{
Luciano F. Boesel ${ }^{\mathrm{a}, \mathrm{b}, *}$, Rui L. Reis ${ }^{\mathrm{a}, \mathrm{b}}$ \\ a3B's Research Group - Biomaterials, Biodegradables and Biomimetics, University of Minho, Campus of Gualtar, 4710-057 Braga, Portugal \\ ${ }^{\mathrm{b}}$ Department of Polymer Engineering, University of Minho, Campus of Azurém, 4800-058 Guimarães, Portugal
}

Received 20 April 2006; accepted 19 July 2006

Available online 9 August 2006

\begin{abstract}
Physiological fluids will be in contact with the implant components from the first moments after a surgery. Therefore, the study of the effect of water on the properties of the bone cements that are part of the arthroplasty procedure is of critical importance to predict the long-term performance of the whole system. In our research group, we have developed a novel concept, the hydrophilic, partially degradable and bioactive cements which uptake considerably more water than standard bone cements. In this paper, we aimed to study the effect of water uptake (WU) by these cements on their behaviour. The tests were carried out in confined cavities, which represent more accurately the in vivo situation the cement will face (constrained by the bone and prosthesis surfaces). We observed that the equilibrium WU decreased up to $60 \%$ (as compared to non-confined situations), depending of the formulation. This decrease resulted in a latent tendency of the cements to swell, and the hindering of such swelling generated a swelling pressure against the constraining walls. The pressure, and consequent press-fitting effect, could be controlled by a number of mechanisms, and resulted in higher stability of the hydrophilic cements, expressed as an increase in the push-out force, required to extract the specimens from such constrained cavities. This effect was only observed in hydrophilic cements, not in commercial, hydrophobic ones used as controls. We conclude that such cements will provide an additional and very useful source of immediate adhesion in the short-term after surgery: water induced press fitting.

C) 2006 Elsevier Ltd. All rights reserved.
\end{abstract}

Keywords: Press-fitting; Swelling; Acrylic cements; Starch; Interfaces

\section{Introduction}

Interfaces in total hip arthroplasties (THA) are one of the key characteristics that should be controlled in order to achieve successful implantation. The interfaces are weak and prone to fractures due to the lack of strong bonding of cement with either metals or bone: it does not possess chemical adhesion with either material, and the interface relies upon interdigitation/mechanical interlocking with the interstices of bone and with the surface roughness of the prosthesis. Accordingly, implants with higher surface roughness were found to improve fixation, since it allows higher surface contact with the cement as well as deeper interdigitation [1,2]. On the other hand, using lower

\footnotetext{
*Corresponding author. Department of Polymer Engineering, University of Minho, Campus of Azurém, 4800-058 Guimarães, Portugal.

E-mail address: 1fboesel@dep.uminho.pt (L.F. Boesel).
}

viscosity bone cements and pressurization devices, the amount of cement penetrating bone can be increased, which increases the interfacial strength with bone [3,4]. Other alternatives have been the use of a pre-coated stem $[5,6]$, cement pre-cooling or pre-heating [7], stem preheating [7] and adhesive cements, containing a monomer able to bond chemically to metals [8]. Last, the development of bioactive cements, able to bond directly to the bone after implantation (biological fixation), has been shown to markedly increase the interfacial bond strength with bone [3,7-10].

Although a number of reports have demonstrated the ability of such modifications to increase the strength of the interfaces, they all possess drawbacks which are a cause for concern. Examples of such drawbacks include: decreased working time due to cement pre-heating, increased leaching of monomers due to the use of lower viscosity bone cements or to cement pre-cooling, increased number of 
peak local contact stresses in the cement mantle due to higher surface roughness [11], lower efficiency on the load transfer from the prosthesis to the bone due to increased modulus of bioactive cements, time lag between implantation and achievement of biological fixation in bioactive cements and deterioration of the interface caused by water debonding [6], among others.

Hydrophilic, partially degradable and bioactive cements [12-15] contain a hydrogel forming monomer (2-hydroxyethyl methacrylate-HEMA) in the liquid component of the typical bone cement formulation, partially substituted for methylmethacrylate (MMA), in order to adjust the mechanical and the swelling properties of the system. These hydrophilic bone cements also incorporate a starch-based blend that can be degraded in the body and has already been studied for a range of biomedical applications. Our degradation results showed that these cements degrade when formulated with $\alpha$-amylase, which catalyses the degradation of starch [16]. We hypothesize that, due to the hydrophilicity of this system, the cements would be able to exert a 'press-fitting' effect when immersed in constrained, humid environments (such as the femoral cavity), which could provide a source of improved immediate fixation.

The aim of the present study was, therefore, to study the mechanical behaviour of such cements in aqueous, confined environments including: (a) change in the water uptake (WU) profile when the cements were in free or confined environments; (b) pressure generation against constraining walls due to WU; and (c) improvement of the 'push-out' force, that is the force required to extract the specimen from a metallic cylinder.

\section{Materials and methods}

\subsection{Preparation of the formulations}

The solid phase of the cements was constituted by a commercial corn starch/cellulose acetate $\frac{50}{50} \mathrm{wt} \%$ blend (SCA) and, in one formulation, also by the bioactive glass Bioglass ${ }^{\circledR} 45 \mathrm{~S} 5$ (NovaMin Technology Inc., Florida, USA). The liquid was constituted by HEMA and MMA, at a molar ratio of $\frac{1}{2}$ (HEMA/MMA). They were used as received. In one formulation, the liquid was composed of pure HEMA, while in another ethyleneglycol dimethacrylate (EGDMA) was also added as a crosslinker monomer, at a molar concentration of 0.01 with respect to the monomers amount. Benzoyl peroxide powder (BPO) was used as the polymerization initiator at a molar concentration of 0.0072 with respect to the monomer amount. Dimethyl-p-toluidine (DMT) was used as the activator of the initiator, at a molar concentration of 0.67 with respect to the BPO amount. The solid/ liquid ratio employed was $\frac{65}{35}$ and the concentration of the glass, when used, was fixed at $32.5 \mathrm{wt} \%$ of the total mass (that is, $50 \mathrm{wt} \%$ of the solid component). Last, one formulation contained a thermostable $\alpha$-amylase (SPEZYME ${ }^{\circledR}$ FRED, $20700 \mathrm{LU} / \mathrm{mL}$ ), supplied by Genencor International B.V. (Leiden, The Netherlands) in the liquid form. The composition of the various formulations is shown in Table 1 .

Liquid and solid phases were mixed and stirred by hand until the mixture became paste like with a high viscosity; the mass was then placed into a poly(tetrafluoroethylene) mold to allow it to cure. The mold had six cylindrical cavities, for specimens with dimensions $12 \mathrm{~mm}$ in height and $6 \mathrm{~mm}$ in diameter.

\subsection{Determination of WU under free and constrained conditions}

For the free environment case, cylindrical specimens were immersed in distilled water and incubated at $37^{\circ} \mathrm{C}$ under static conditions. The specimens were removed at pre-determined intervals, rinsed with distilled water, blotted on filter paper to remove surface water and immediately weighed. They were then immersed again in the water until the last time point.

WU was calculated using the following equation:

$\mathrm{WU}_{t}=\left(\frac{m_{t}-m_{\mathrm{f}}}{m_{\mathrm{f}}}\right) \times 100$,

where $m_{t}$ is the wet mass of the specimen at time $t$ (days) and $m_{\mathrm{f}}$ is the final mass after immersion and drying.

For the constrained environment case, the specimens were first inserted into stainless steel capsules (cylinders with $12 \mathrm{~mm}$ height, $6 \mathrm{~mm}$ internal diameter, $10 \mathrm{~mm}$ external diameter and 18 channels with $2 \mathrm{~mm}$ diameter homogeneously distributed along the cylinder) and then mounted between two clamping plates to restrict axial swelling. The whole system was immersed in distilled water and incubated at $37^{\circ} \mathrm{C}$ under static conditions. The procedure was then the same as above.

\subsection{Measurement of the swelling force (press-fitting test)}

The bone cement specimens, with a cross sectional area of $28.3 \times 10^{-6} \mathrm{~m}^{2}$, were mounted in a MINIMAT miniature testing machine (Polymer Laboratories, USA), employing the same metal capsules described above, a small acrylic water bath and a thermocouple to control the temperature. The top and bottom surfaces of the specimen were connected to the grips of the instrument, the upper one being connected to a load cell with capacity to $200 \mathrm{~N}$. The cement could uptake water only through the 18 channels, and was not allowed to swell, being the force exerted recorded as a function of time. Maximum test time was $100 \mathrm{~h}$ (at room temperature) or $10 \mathrm{~h}\left(\right.$ at $\left.37^{\circ} \mathrm{C}\right)$. The surface morphology of the specimens after press-fitting test was analysed with a Leica Cambridge S360 (Leica Cambridge Ltd, UK) scanning electron microscope (SEM).

Table 1

Formulations used in this study and their respective nomenclature

\begin{tabular}{lllll}
\hline Formulation & & Solid component $(65 \%)$ & Liquid component $(35 \%)$ & Description \\
\hline HDBC & B & SCA + BPO & MMA/HEMA $(2 / 1)+$ DMT & Base formulation \\
& E & SCA + BPO & MMA/HEMA $(2 / 1)+$ DMT $+\alpha$-amylase $(0.10$ mL) & Formulation with enzyme \\
& G & SCA $/ 45 S 5(1 / 1)+$ BPO & MMA/HEMA $(2 / 1)+$ DMT & Bioactive formulation \\
& H & SCA + BPO & HEMA + DMT & More hydrophilic formulation \\
& X & SCA + BPO & MMA/HEMA $(2 / 1)+$ EGDMA $(0.01$ mol/mol $)+$ & Crosslinked formulation \\
Palacos-R & & & DMT & Commercial formulation \\
\hline
\end{tabular}


Before observation, specimens were gold-coated by ion sputtering (Sputter Coater SC502, Fisons Instruments, UK).

\subsection{Measurement of the "push-out" force}

The cylindrical cement specimens were first cut to $10 \mathrm{~mm}$ height and subsequently mounted with the same setup described in Section 2.2 (a $2 \mathrm{~mm}$ thick disk was employed on top of the specimen to avoid swelling). After pre-determined time periods, the capsule + specimen was removed from the water bath and the $2 \mathrm{~mm}$ thick disk was replaced by a $2 \mathrm{~mm}$ thick stainless steel piston. The system capsule + specimen + piston was subsequently mounted on an Universal Mechanical Testing Machine Instron model 4505 (Instron, USA), with a load cell of $50 \mathrm{kN}$. The piston was connected to the load cell (upper grip) and the capsule was adapted on a metal support with a central hole of $8 \mathrm{~mm}$ diameter. The bottom grip (to which the capsule was connected) was moved up with a speed of $1 \mathrm{~mm} / \mathrm{min}$ $\left(1.67 \times 10^{-5} \mathrm{~m} / \mathrm{s}\right)$, and the force was followed as a function of crosshead movement.

\subsection{Statistical analysis}

Due to the large number of non-normal samples, Mann-Whitney's $U$ tests (non-parametric test) were performed to test differences among all the samples. In all tests, the level of significance was fixed at $p<0.05$.

\section{Results and discussion}

As depicted in Fig. 1 for three formulations of hydrophilic cements, the behaviour of WU was very different when the specimens were in a free or in a constrained environment. In fact, when in the confined situation, the specimens were not allowed to swell due to the constrained environment of the capsule. As a consequence they could only uptake water while the matrix could accommodate it without changes in volume (that is, in the excess free volume and/or in pores). After all the sorption sites were filled, the uptake ceased at a value much lower than would be obtained in the case of free swelling.

Another feature that can be concluded from Fig. 1 was that the possibility of tailoring the WU became relevant only if the equilibrium level of $\mathrm{WU}$ in the free state was lower than the maximum WU in the constrained environment. While in the free environment we could fine-tune the WU by means of adding a crosslinker (which decreases the mobility of the chains and the sorption capacity of the matrix) or an thermostable enzyme (which, being water soluble, increases the hydrophilic character of the matrix), these modifications had no relevance in the constrained environment.

If the cements uptake water and are not allowed to swell, one could expect they would exert a "swelling force" on the constraining walls. Fig. 2 displays the swelling force exerted by several specimens under different conditions, while Table 2 shows a summary of the results obtained at $37^{\circ} \mathrm{C}$. Clearly, only the hydrophilic cements were able to create a swelling force effect. This is confirmed in Fig. 2B where, for longer testing periods ( $\sim 4$ days), the difference among the formulations with higher or lower hydrophilic character were more evident; the swelling force was even
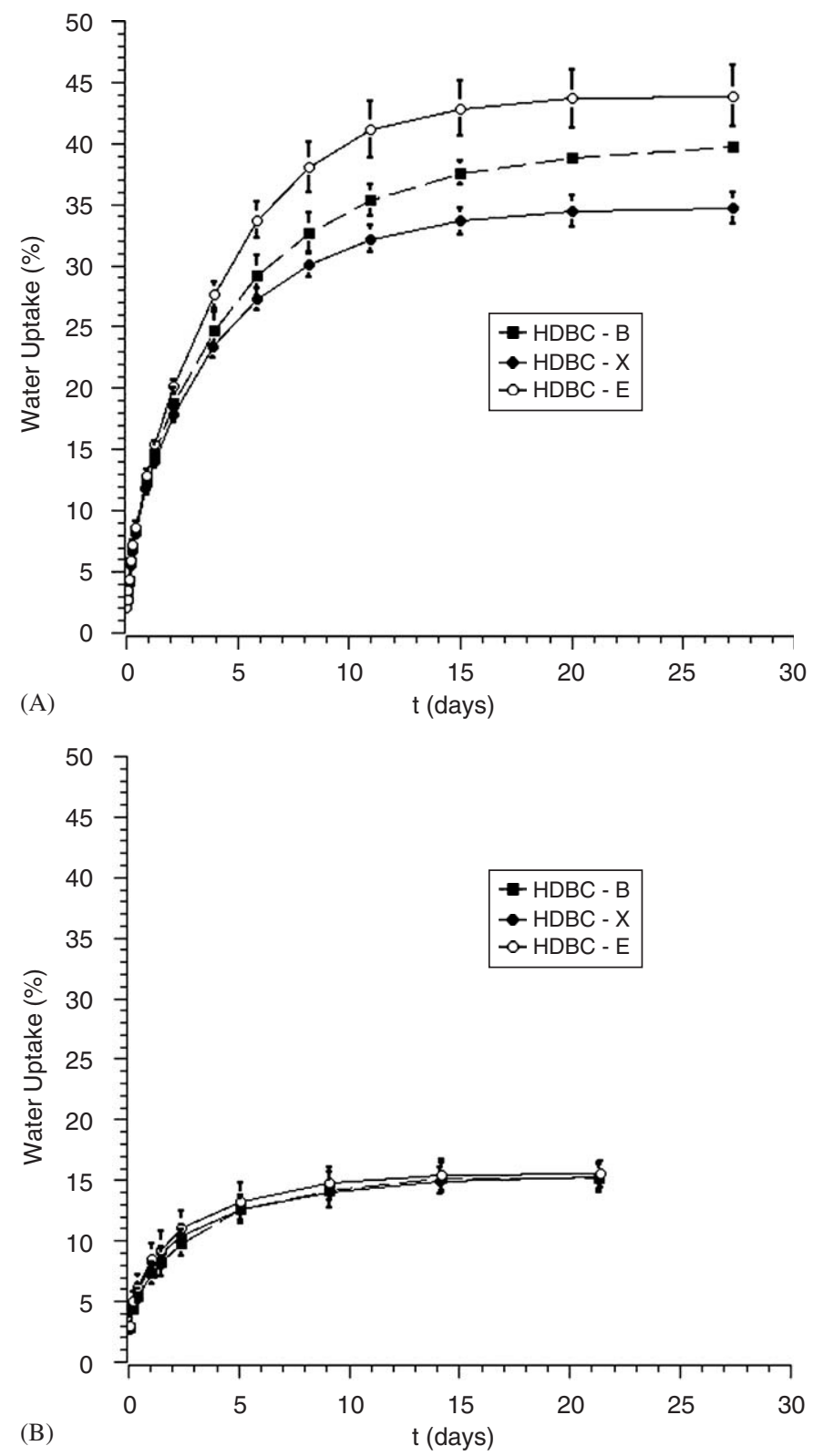

Fig. 1. Water uptake of three HDBC formulations under free (A) and constrained (B) conditions.

higher for a formulation $(\mathrm{H})$ containing only HEMA which has a stronger hydrophilic character.

Independently of the formulation under consideration, the swelling force was always much higher than those presented by a commercial bone cement under the same conditions (Fig. 2(A) and (B)).

One of the most important features of the swelling force behaviour is that it can partially (or totally, if correctly adjusted) compensate for the shrinkage residual stresses arising during polymerization of bone cement in confined environments. These residual stresses appear as a result of pure density changes or to thermal shrinkage [17]. Besides potentiating the failure of the cement at low stress levels, shrinkage also causes an increased level of porosity formation, especially at the stem-cement interface, where 

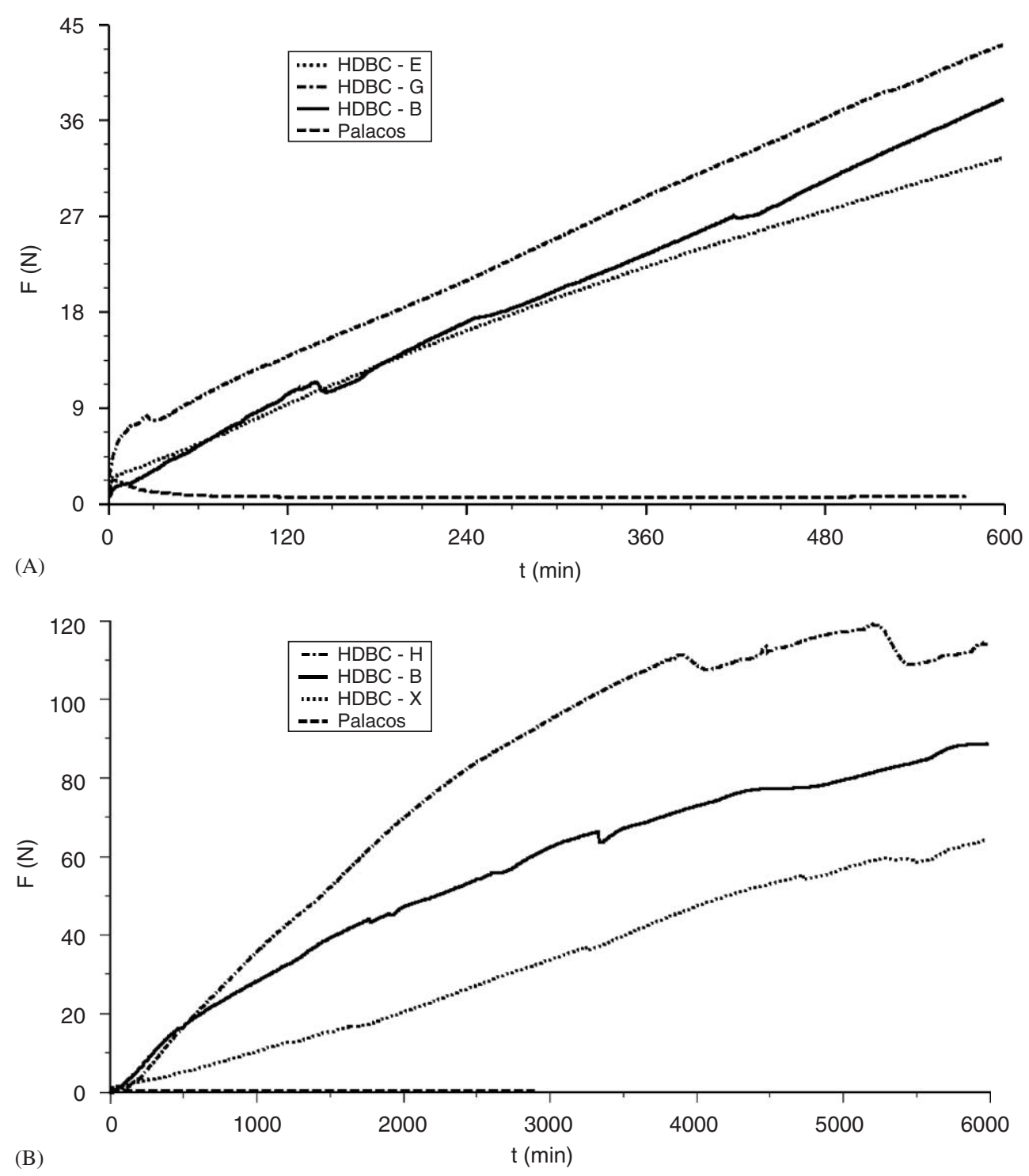

Fig. 2. Swelling force at different conditions: (A) $37^{\circ} \mathrm{C}$ and (B) $20^{\circ} \mathrm{C}$.

Table 2

Summary of the swelling force results at $37^{\circ} \mathrm{C}$

\begin{tabular}{llll}
\hline Formulation & & Max. load $(\mathrm{N})$ & Slope $(\mathrm{mN} / \mathrm{min})$ \\
\hline B & $4 \mathrm{~mm}$ & $13.0 \pm 2.0$ & $22.8 \pm 0.1$ \\
& $8 \mathrm{~mm}$ & $20.0 \pm 0.9$ & $29.5 \pm 3.4$ \\
& $12 \mathrm{~mm}$ & $32.2 \pm 0.7$ & $51.4 \pm 1.6$ \\
HDBC & B & $32.2 \pm 0.7$ & $51.4 \pm 1.6$ \\
& G & $43.6 \pm 2.6$ & $67.7 \pm 9.4$ \\
& E & $33.1 \pm 5.0$ & $50.3 \pm 10.5$ \\
Palacos $^{\circledR}-\mathrm{R}$ & & $2.0 \pm 1.1$ & $0.3 \pm 0.2$ \\
\hline
\end{tabular}

polymerization is thought to start. Different authors have studied the phenomena, arriving at final shrinkage values as high as $10 \mathrm{MPa}$ (tensile) [17], $25 \mathrm{MPa}$ (circumferential) [18] or $7 \mathrm{MPa}$ [19]. The failure scenario could begin even before weight-bearing due to cracking induced by residual stress around pores or stress raisers [19]. Therefore, a mechanism providing stress relaxation would be strongly beneficial for the stability of the cement. WU would, in a first moment, increase the mobility of the chains (plasticization), which could then rearrange themselves in new conformations, relieving part of the residual stress. Additionally, the pressure induced by impeded swelling would act on the opposite direction of the shrinkage stresses (that is, compression), also contributing in this way to decrease the magnitude of these stresses. Considering a testing area of $28.3 \times 10^{-6} \mathrm{~m}^{2}$, the maximum swelling pressure obtained in this study (at 4 days and $20^{\circ} \mathrm{C}$ ) was approximately $4.2 \mathrm{MPa}$, which is in the same order of magnitude of the residual stresses. As shown in Fig. 2, this value could be easily tailored by even minute changes in the cement formulation. Pascual et al. [20] have also shown that changes in the formulation of a MMA/HPMA (hydroxypropyl methacrylate) system could provide a composition whose swelling exactly matches the dimensional changes due to polymerization shrinkage. 
Another point to consider is the influence of thickness on the shrinkage. With higher thickness of the cement layer one would expect a higher shrinkage and, consequently, a higher magnitude of residual stresses. Table 2 shows the effect of cement thickness (here represented by the height of the cylinder) on the swelling force. The most important feature is that our novel systems are capable of adjusting the response to the magnitude of the shrinkage, even for a fixed formulation: the higher the shrinkage stresses (due to higher thickness), the higher the counteracting swelling pressure.

Considering now the opposite interface (that is, cementbone), it has been shown that its strength is a function of its thickness, defined as the depth of penetration of cement inside cancellous bone. Therefore, increasing the penetration depth promotes increase in the interfacial strength $[3,4]$. The hydrophilic cements are able to provide a method of increased interdigitation with bone, as shown in Fig. 3. The surface of Palacos ${ }^{\circledR}-R$ was flat, as in the beginning of the test, indicative of no changes at the interface. On the other hand, HDBC-B displayed some protruding disks on the surface, which corresponded (in size and position) to the free volume of the channel for WU. In fact, these were the only spaces where the cement surface was not constrained and, as shown in Fig. 3(B), the cement could swell (at a micro-scale) against this space while the rest of the specimen was "locked". Moreover, at higher magnifications (Fig. 3(C)), we observed the specimen adapting its whole surface to the surface irregularities of the metal capsule, which contained striations along the $r$ axis (the capsule was finished but not polished). These are strong indications that, in vivo, the cement will be able to locally swell against the interstices of bone, increase the penetration depth while keeping the integrity of the interface.

Both the swelling force and increased interdigitation were expected to promote a higher stability of the cement, represented as an increase in the "push-out" force required to extract the specimen from confined cavities. We submitted formulations to this test after different periods of time; the results for two of them (one specimen per formulation per time period) are in Fig. 4. The differences in $\mathrm{P}$ and $\mathrm{B}$ are evident and are clearly assigned to the mechanisms discussed previously. When we performed the test with specimens pre-shaped and inserted into the capsule after polymerization, we avoided any influence of mechanical interlocking and/or chemical adhesion arising during polymerization. With this test setup, we were able to isolate the effect of $\mathrm{WU}$, which was the only one taking place.

The effect of water induced press fitting was evident for the hydrophilic cements since the first day of immersion. Interestingly, the values did not increase much after the first day, showing that at very early stages of implantation the effect would be already actuating. Fig. 5 displays the results for all formulations and test periods. All experimental formulations were significantly higher than $\mathrm{P}$, confirming their ability to promote a higher stability of
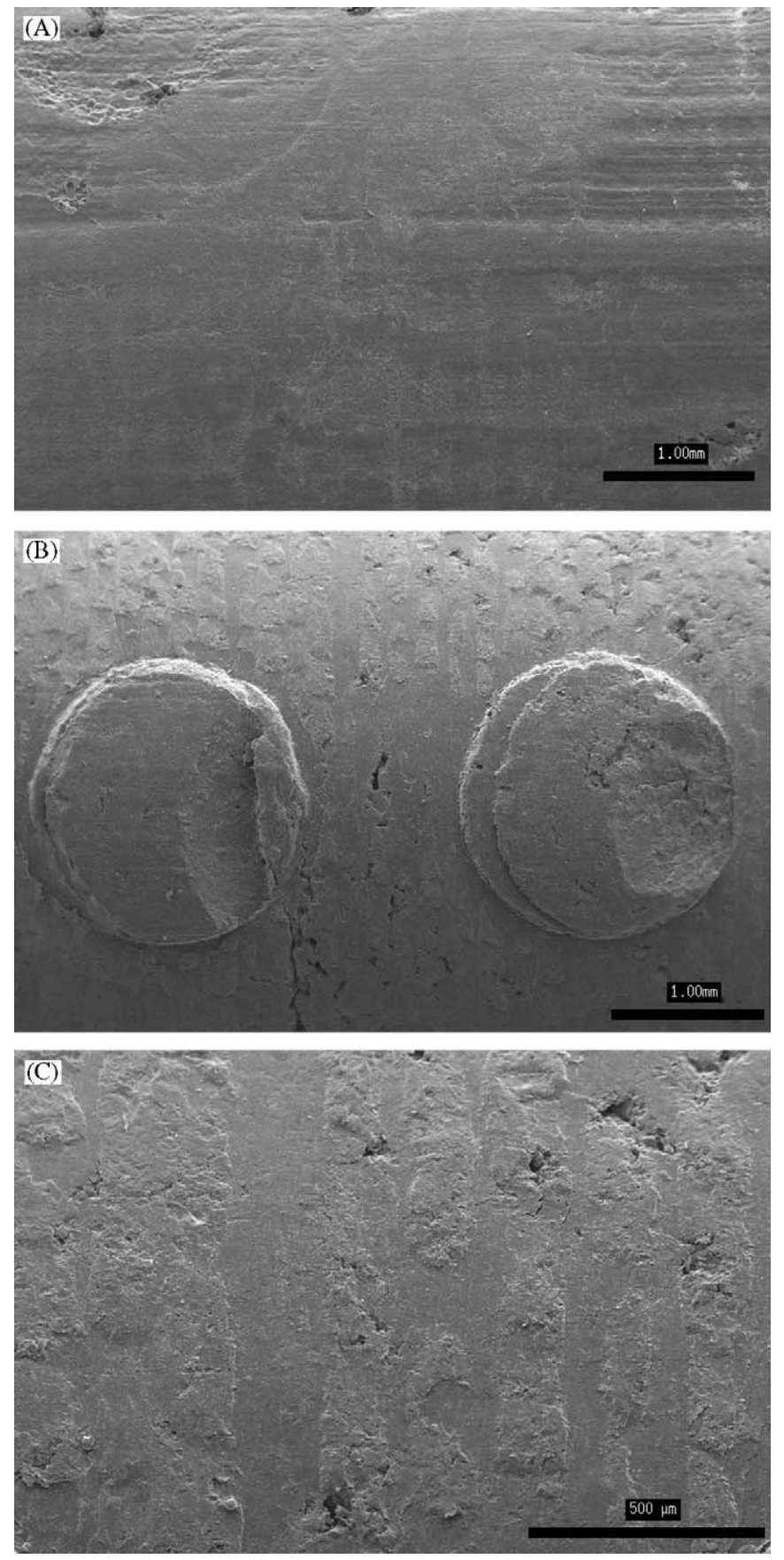

Fig. 3. SEM micrographs of the surface of specimens after being submitted to press-fitting tests: (A) Palacos ${ }^{\mathbb{R}}-\mathrm{R}$, (B) and (C) HDBC-B.

the implants. Moreover, this increased push-out force would be relevant as soon as the cement starts to uptake water. In other words, it would provide an additional source of interfacial adhesion (to both bone and prosthesis) when it is more needed, that is, in the first days postsurgery.

\section{Conclusions}

We have shown that hydrophilic, partially degradable and bioactive cements have different behaviour in terms of 


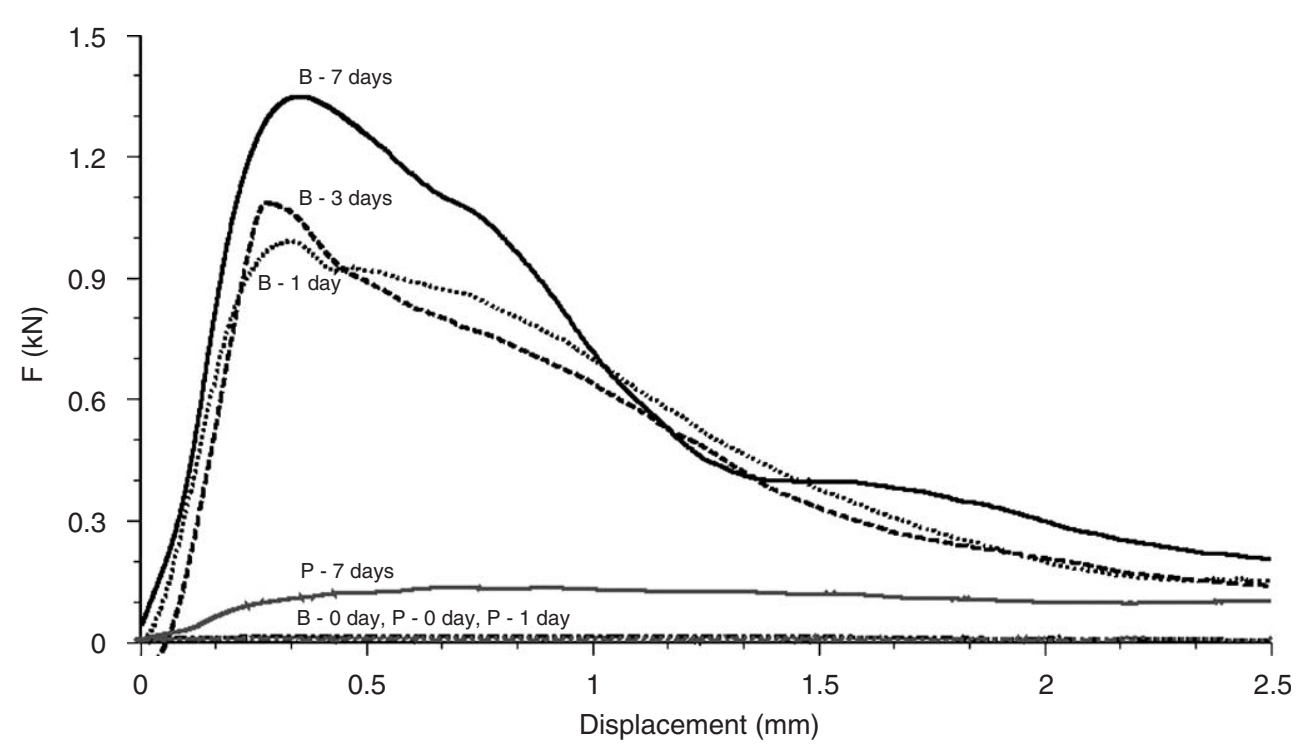

Fig. 4. Push-out curves for two formulations (Palacos and HDBC-B), after several immersion periods.

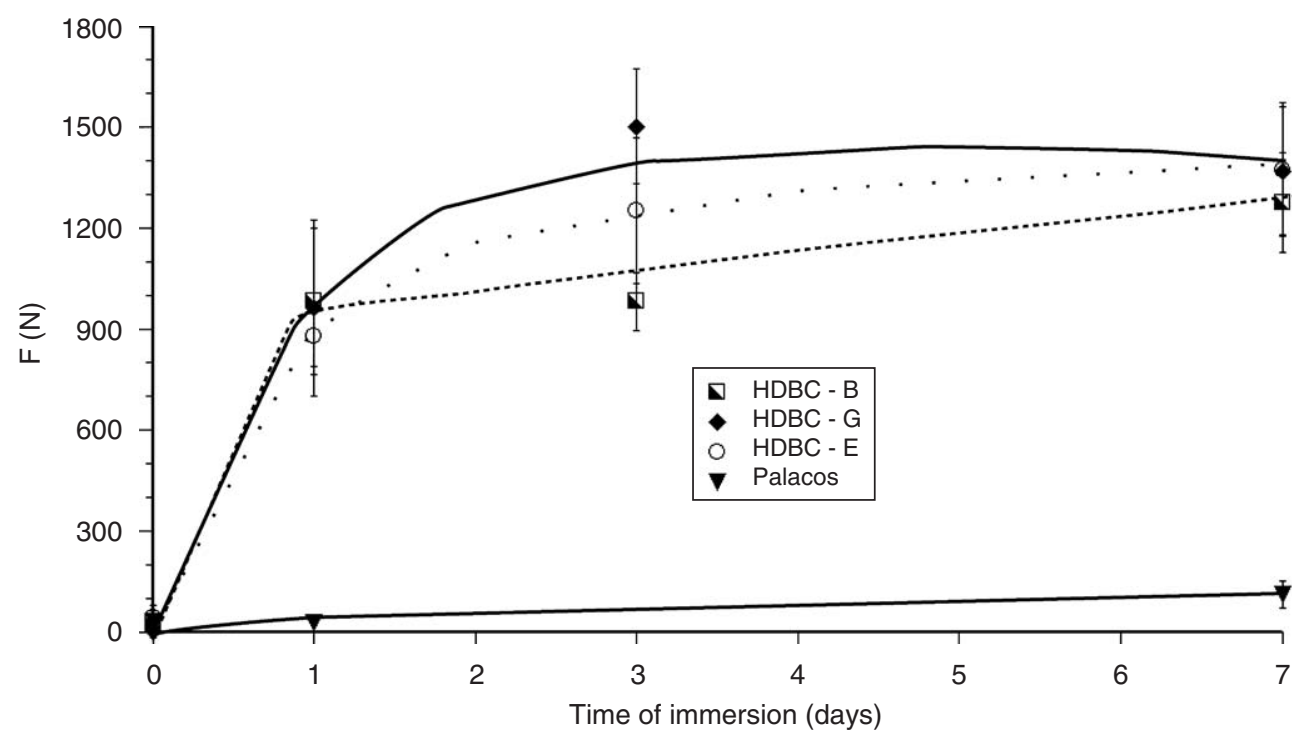

Fig. 5. Summary of push-out results for all tested formulations. Significant differences were as follows: Palacos: d7 (= sample tested after 7 days of immersion) significant against other time periods; $\mathrm{d} 1$ and $\mathrm{d} 7$ significant against other cements (at the corresponding time periods); HDBC - $\mathrm{B}$ : $\mathrm{d} 0$ and $\mathrm{d} 7$ significant against other time periods, d3 significant against other HDBC cements; HDBC - G: d0 and d1 significant against other time periods; HDBC E: $\mathrm{d} 0$ and $\mathrm{d} 1$ significant against other time periods.

their WU ability when they are in free or confined environments. This difference, which gives rise to a latent tendency to swell which is impeded by the constrained environment, is reflected in a swelling force exerted by the cement against the confining walls. This force will be increased when the difference between WU in the free and in the confined environments are higher. The water uptaken by the cement therefore is able to increase the depth of penetration into bone interstices and, as a consequence, will improve the fixation of the prosthesis and the stability of the implant. This was verified experimentally, through a modified push-out test. This property is a major advantage of HDBCs when compared to the cements presently used in the clinical arena.

\section{Acknowledgements}

We thank Prof. João Mano and Prof. Nuno Neves for fruitful discussions on the design of the press-fitting and push-out experiments. L.F. Boesel acknowledges Fundação Coordenação de Aperfeiçoamento de Pessoal do Ensino Superior (CAPES - Brasília, Brazil) for the PhD grant. This work was partially supported by FCT, through funds from the POCTI and/or FEDER programmes. 


\section{References}

[1] Walsh WR, Svehla MJ, Russell J, Saito M, Nakashima T, Gillies $\mathrm{RM}$, et al. Cemented fixation with PMMA or Bis-GMA resin hydroxyapatite cement: effect of implant surface roughness. Biomaterials 2004;25:4929-34.

[2] Mann KA, Ayers DC, Werner FW, Nicoletta RJ, Fortino MD. Tensile strength of the cement-bone interface depends on the amount of bone interdigitated with PMMA cement. J Biomech 1997;30: 339-46.

[3] Dunne NJ, Orr JF, Beverland DE. Assessment of cement introduction and pressurization techniques. P I Mech Eng H 2004;218:11-25.

[4] Lucksanasombool P, Higgs WAJ, Ignat M, Higgs RJED, Swain MV. Comparison of failure characteristics of a range of cancellous bone-bone cement composites. J Biomed Mater Res A 2003;64A: 93-104.

[5] Yerby SA, Paal AF, Young PM, Beaupré GS, Ohashi KL, Goodman SB. The effect of a silane coupling agent on the bond strength of bone cement and cobalt-chrome alloy. J Biomed Mater Res 2000;49: 127-33.

[6] Fischer H, Wirtz DC, Weber M, Neuss M, Niethard FU, Marx R. Improvement of the long-term adhesive strength between metal stem and polymethylmethacrylate bone cement by a silica/silane interlayer system. J Biomed Mater Res 2001;57:413-8.

[7] Iesaka K, Jaffe WL, Kummer FJ. Effects of the initial temperature of acrylic bone cement liquid monomer on the properties of the stem-cement interface and cement polymerization. J Biomed Mater Res B 2004;68B:186-90.

[8] Morita S, Yamamoto H, Furuya K, Ishihara K, Nakabayashi N. Enhanced strength in cemented stem fixation using adhesive acrylic cement as a metal coating material. J Biomed Mater Res 1997;34: $171-5$.

[9] Kamimura M, Tamura J, Shinzato S, Kawanabe K, Neo M, Kokubo $\mathrm{T}$, et al. Interfacial tensile strength between polymethylmethacrylatebased bioactive bone cements and bone. J Biomed Mater Res 2002; 61:564-71.
[10] Kobayashi M, Nakamura T, Okada Y, Fukumoto A, Furukawa T, Kato $\mathrm{H}$, et al. Bioactive bone cement: comparison of apatite and wollastonite containing glass-ceramic, hydroxyapatite, and $\beta$-tricalcium phosphate fillers on bone-bonding strength. J Biomed Mater Res 1998;42:223-37.

[11] Kawanabe K, Yamamuro T, Nakamura T, Kokubo T, Yoshihara S, Shibuya T. A new bioactive bone cement consisting of bis-GMA resin and bioactive glass powder. In: International symposium on ceramics in medicine, Proceedings, vol. 5. Kyoto, 1992. p. 233-9.

[12] Boesel LF, Mano JF, Elvira C, San Román J, Reis RL. In: Chiellini E, Solaro R, editors. Hydrogels and hydrophilic partially degradable bone cements based on biodegradable blends incorporating starch. New York: Kluwer Academic/Plenum Press; 2003. p. 243-60.

[13] Pereira CS, Cunha AM, Reis RL, Vázquez B, San Román J. New starch-based thermoplastic hydrogels for use as bone cements or drug-delivery carriers. J Mater Sci Mater Med 1998;9(12):825-33.

[14] Espígares I, Elvira C, Mano JF, Vázquez B, San Román J, Reis RL. New partially degradable and bioactive acrylic bone cements based on starch blends and ceramic fillers. Biomaterials 2003;23(8):1883-95.

[15] Boesel LF, Mano JF, Reis RL. Optimization of the formulation and mechanical properties of starch based partially degradable bone cements. J Mater Sci Mater Med 2004;15:73-83.

[16] Boesel LF, Reis RL. Hydrophilic matrices to be used as bioactive and degradable bone cements. J Mater Sci Mater Med 2004;15:503-6.

[17] Roques A, Browne M, Taylor A, New A, Baker D. Quantitative measurement of the stresses induced during polymerisation of bone cement. Biomaterials 2004;25:4415-24.

[18] Orr JF, Dunne NJ, Quinn JC. Shrinkage stresses in bone cement. Biomaterials 2003;24:2933-40.

[19] Lennon AB, Prendergast PJ. Residual stress due to curing can initiate damage in porous bone cement: experimental and theoretical evidence. J Biomech 2002;35:311-21.

[20] Pascual B, Goñi I, Gurruchaga M. Characterization of new acrylic bone cement based on methyl methacrylate/1-hydroxypropyl methacrylate monomer. J Biomed Mater Res Appl Biomater 1999;48: $447-57$. 